\title{
Polimorfismos genéticos da kappa-caseína e da beta-lactoglobulina e produção de leite em bovinos
}

\author{
[Kappa-casein and beta-lactoglobulin genetic polymorphisms and milk yield in bovines] \\ A.T. Stipp ${ }^{1}$, P.R. Bignardi ${ }^{1}$, R.C. Poli-Frederico ${ }^{1}$, K. Sivieri ${ }^{2}$, M.R. Costa $^{3} *$ \\ ${ }^{1}$ Universidade Norte do Paraná - UNOPAR - Londrina, PR \\ ${ }^{2}$ Universidade Estadual Paulista - UNESP - Araraquara, SP \\ ${ }^{3}$ Universidade Federal de Mato Grosso do Sul - UFMS - Campo Grande, MS
}

\begin{abstract}
RESUMO
As variantes gênicas da beta-lactoglobulina $(\beta-L G)$ e da kappa-caseína $(k-C N)$ bovinas são associadas à produção, qualidade e características de processamento do leite. O objetivo deste trabalho foi analisar as frequências dos genótipos $\mathrm{AA}, \mathrm{AB}$ e BB, por meio da técnica de PCR-RFLP, da $\beta$-LG e da k-CN bovinas, e suas associações com a produção de leite ( $\mathrm{kg}$ leite/dia) em bovinos das raças Girolanda, Holandesa e Jersey. Para a k-CN, a frequência do genótipo AA foi maior nos animais das raças Holandesa (37\%) e Girolanda (63\%). Na raça Jersey, houve predomínio do genótipo BB (60\%). Para a $\beta$-LG, o genótipo AB foi o mais encontrado nas raças Girolanda (54\%) e Holandesa (58\%), enquanto nos animais da raça Jersey houve predomínio do genótipo BB (45\%). Houve associação do alelo B da k-CN com maior produtividade leiteira nas raças Girolanda e Holandesa, e do alelo A da $\beta$-LG com maior produtividade de leite na raça Jersey. As variantes genéticas da k-CN podem ser usadas como marcadores na seleção para a produtividade leiteira nas raças Girolanda e Holandesa. Para a raça Jersey, as variantes da $\beta$-LG seriam mais adequadas para essa seleção.
\end{abstract}

Palavras-chave: leite, proteínas do soro do leite, caseínas, frequência de genótipos

\begin{abstract}
Bovine beta-lactoglobulin $(\beta-L G)$ and kappa-casein $(\kappa-C N)$ genic variants are associated with productivity, quality and processing features of milk. The objective of this study was to analyze through the PCR-RFLP technique, the frequency of $A A, A B$ and BB genotypes of bovine $\beta-L G$ and $\kappa-C N$, and their association to milk production ( $k g$ milk/day) in Girolanda, Holstein and Jersey cattle. For $k$ - CN, the frequency of the AA genotype was higher in Holstein (37\%) and Girolanda (63\%), while there was a predominance of the BB genotype in Jersey (60\%). For $\beta-L G$, the BB genotype was the most found in Girolanda (54\%) and Holstein (58\%), while there was a predominance of the BB genotype (45\%) in Jersey. There was a positive association between $B$ allele of $k-C N$ and milk production in the Girolanda and Holstein cattle and between A allele of $\beta$-LG and milk production in the Jersey cattle. Genetic variants of $k-C N$ could be used as markers for the selection for productivity in Girolanda and Holstein cattle. The genetic variants of $\beta-L G$ would be more appropriate for this selection in the Jersey breed.
\end{abstract}

Keywords: milk, whey proteins, caseins, frequency of genotypes

\section{INTRODUÇÃO}

O polimorfismo genético com relação às proteínas lácteas, em particular kappa-caseína $(\mathrm{k}-\mathrm{CN})$ e beta-lactoglobulina $(\beta-\mathrm{LG})$, tem

Recebido em 16 de junho de 2011

Aceito em 10 de setembro de 2012

* Autor para correspondência (corresponding author)

Email: marcela.rezende@ufms.br sido associado a diferenças na composição, características de processamento e qualidade do leite, além de parâmetros de produtividade (Lin et al., 1986; Aleandri et al., 1990; Fox e McSeweeney, 2003). Diferentes versões de uma sequência de DNA em um determinado local 
cromossômico (locus) são chamadas de alelos. O polimorfismo genético ocorre quando diferentes formas alélicas de um mesmo locus gênico podem ser observadas na frequência de pelo menos $1 \%$ em uma população (Watson e Berry, 2006).

A beta-lactoglobulina foi a primeira proteína láctea na qual o polimorfismo foi detectado (Aschaffenburg e Drewry, 1955). Desde então, foram descobertos polimorfismos nos genes que codificam as caseínas e grande parte das principais proteínas do soro do leite (Fox e McSweneey, 2003). Diferenças entre genótipos podem alterar a estrutura primária das proteínas e resultar em alterações de suas propriedades físico-químicas (Hill et al., 1996).

Dentre as cinco variantes genéticas principais, A-E, da $\beta$-LG em bovinos, A e B são as mais frequentes. A $\beta$-LG apresenta uma molécula com 162 aminoácidos e as variantes A e B diferem nas posições 64 e 118. A variante A possui ácido aspártico na posição 64 e valina na 118 , enquanto a variante B apresenta glicina e alanina nessas posições (Fox e McSweneey, 2003).

Já foram encontradas diversas variantes genéticas da $\mathrm{k}-\mathrm{CN}$, sendo $\mathrm{A}$ e $\mathrm{B}$ as mais frequentes. As variantes A e B diferem nos aminoácidos 136 e 148, respectivamente. Para a variante A na posição 136, a treonina é substituída por isoleucina; e na posição 148 , para a variante B, o ácido aspártico é substituído por alanina (Alexander et al., 1988).

A $\beta$-LG é a proteína encontrada em maior concentração no soro de leite bovino, representando cerca de $50 \%$ das proteínas do soro e $12 \%$ do total de proteína no leite. Já a k-caseína, apesar de estar em relativamente baixa proporção comparada às outras caseínas (12\%), é essencial na estabilização das micelas de caseínas no leite (Walstra et al., 2006).

A identificação de genes polimórficos que codificam as principais proteínas do leite pode permitir uma melhor compreensão do comportamento do leite durante o processamento pela indústria (Paterson et al., 1999). Esses genes que codificam as proteínas do leite podem ser úteis como marcadores genéticos para critérios de seleção e cruzamentos de animais de gado leiteiro. Além disso, investigações de associações entre polimorfismo e características quantitativas e qualitativas do leite podem direcionar sua utilização pela indústria.

O presente estudo teve como objetivos avaliar a frequência dos genótipos $\mathrm{AA}, \mathrm{AB}$ e $\mathrm{BB}$ da kappa-caseína e da beta-lactoglobulina bovinas nas raças Girolanda, Holandesa e Jersey, e verificar a possível associação desses genótipos com a produção de leite.

\section{MATERIAL E MÉTODOS}

A produtividade leiteira de cada animal foi calculada através da média dos últimos seis meses (kg leite/ dia) de lactação.

Para extração do DNA, foram coletados $5 \mathrm{~mL}$ de sangue da circulação periférica, em tubo estéril contendo anticoagulante EDTA $(6 \%)$ de animais das raças Holandesa $(n=38)$, Girolanda $(n=48)$ e Jersey $(n=42)$, previamente selecionados de rebanhos de uma fazenda experimental, Tamarana-PR. Os tubos com sangue foram transportados e mantidos refrigerados até a realização da extração do DNA. O DNA genômico de cada animal foi extraído a partir de $1 \mathrm{~mL}$ da massa leucocitária do sangue coletado, utilizando o PureLink ${ }^{\mathrm{TM}}$ Genomic DNA Extraction Mini kit (Invitrogen Biosicence). O DNA extraído foi mantido em ultrafreezer (-73 a $-80{ }^{\circ} \mathrm{C}$ ) até a realização das análises.

As amostras de DNA foram submetidas à amplificação por meio da reação em cadeia da polimerase (PCR) e à clivagem por meio da técnica de polimorfismo de tamanho de fragmentos de restrição (RFLP) de acordo com os procedimentos descritos por Medrano e Aguilar-Cordoba (1990ab). Os oligonucleotídeos iniciadores (primers) utilizados foram sintetizados (Invitrogen ${ }^{\circledR}$ ) conforme as sequências:

5'ATCATTTATGGCCATTCCACCAAAG3' (JK5) e 5'GCCCATTTCGCCTTCTCTGTAACAGA3' (JK3) para a $\mathrm{k}-\mathrm{CN}$, e

5'GTCCTTGTGCTGGACACCGACTACA3' (BLGP3) e

5'CAGGACACCGGCTCCCGGTATATGA3' (BLGP4) para a $\beta$-LG.

As amplificações foram realizadas em termociclador Multigene II (Labnet International Inc.). Em todas as reações de amplificação, 
utilizou-se um controle negativo (sem DNA), para confirmar a ausência de contaminação na execução da análise. O DNA amplificado foi mantido em ultrafreezer até a realização do RFLP. Para a confirmação da amplificação das amostras, realizou-se eletroforese em gel de agarose a $0,8 \%$, em cuba horizontal de acrílico com tampão de corrida TBE $1 \mathrm{X}$ a 60 volts, por 60 minutos, utilizando SYBR SAFE ${ }^{\circledR}$ como corante.

O produto da PCR passou pela análise de RFLP utilizando as enzimas de restrição Hinf I para k$\mathrm{CN}$ e Hae III para a $\beta$-LG para clivagem a $37^{\circ} \mathrm{C}$ por 12 horas. Os fragmentos de DNA resultantes foram separados em gel de poliacrilamida $6 \%$ com corrida a $70 \mathrm{~V}$ e depois corados com nitrato de prata.

Os resultados obtidos foram analisados por meio de análise de variância e teste Tukey, a 5\% de significância.

\section{RESULTADO E DISCUSSÃO}

$\mathrm{O}$ produto amplificado para a proteína $\mathrm{k}-\mathrm{CN}$ correspondeu a um fragmento de 350 pares de bases (pb), do éxon IV do gene para a $\mathrm{k}-\mathrm{CN}$ bovina. Esse fragmento foi clivado pela endonuclease Hinf I, cujo sítio de reconhecimento é a sequência $\mathrm{G} \downarrow$ ANTC. Como resultado, o genótipo AA apresentou três fragmentos de 132, 134 e 84pb, o genótipo BB, dois de 266 e $84 \mathrm{pb}$, e o genótipo $\mathrm{AB}$, quatro fragmentos de 266, 134, 132 e 84pb.

Para a proteína $\beta$-LG, o produto amplificado do DNA correspondeu a um fragmento de $262 \mathrm{pb}$, do éxon IV do gene da $\beta$-LG. A digestão com a enzima Hae III tem como sítio de reconhecimento a sequência GG $\downarrow$ CC. Para o genótipo AA foram encontradas três bandas de 153,79 e $74 \mathrm{pb}$, para o genótipo BB, três bandas de 109, 79 e 74pb, e para o genótipo $\mathrm{AB}$, quatro bandas de 153, 109, 79 e 74pb. Na Fig. 1 mostram-se as frequências genotípicas encontradas nas três raças estudadas.

Para a k-CN, a raça Girolanda apresentou maior número de animais com genótipo $\mathrm{AA}, 63 \%$, enquanto a Jersey apresentou maior frequência do genótipo $\mathrm{BB}, 60 \%$. Na raça Holandesa foram encontradas frequências similares para os três genótipos possíveis, $\sim 30 \%$ cada. Botaro et al. (2009) avaliaram rebanhos do interior do estado de São Paulo e encontraram uma frequência do genótipo AA de $67 \%$ na raça Girolanda e de $71 \%$ na raça Holandesa. Buchberger (1995) relatou menores frequências do alelo A na raça Jersey, que variou entre 0,49 e 0,32. A alta frequência do alelo A do gene da k-CN na raça Girolanda provavelmente está relacionada à sua origem em cruzamentos das raças Gir e Holandesa. Sabe-se que há uma alta frequência do genótipo AA na raça Gir (Valente, 1996; Rodrigues, 2006).
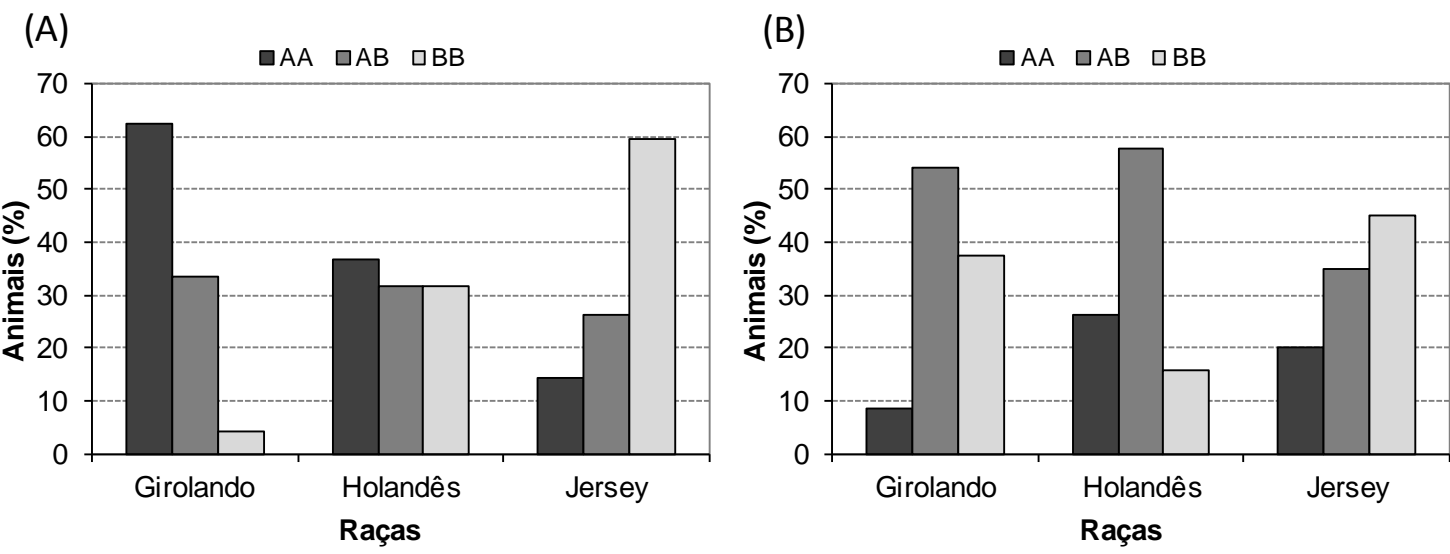

Figura 1. Distribuição dos genótipos relativos à kappa-caseína (A) e à beta-lactoglobulina (B) de acordo com a raça.

Relatos da literatura apontam que o alelo B da kappa-caseína tem efeito significativo sobre a qualidade do leite para a produção de queijo
(Mao et al., 1992). Van der Berg et al. (1992) encontraram alta frequência do alelo $B$ na raça Jersey e afirmaram que a presença desse alelo 
contribuiu com 8 a 10\% na composição proteica do leite. Assim, o leite produzido por vacas de genótipo $\mathrm{BB}$ mostraram maior rentabilidade na produção de queijos quando comparadas às vacas de genótipo AA.

Ng-Kwai-Hang et al. (1987) verificaram que o leite de animais com genótipo $\mathrm{BB}$ para a k-CN apresenta maiores teores de $\alpha \mathrm{s} 1-\mathrm{CN}, \kappa-\mathrm{CN}$, soroalbumina e imunoglobulinas, e menores de $\beta$-CN, $\beta$-LG e $\alpha$-La. O alelo B, em geral, também é associado às melhores características para o processamento industrial do leite. A utilização de leite oriundo de animais com esse genótipo resulta em menor tempo de coagulação para o preparo de queijo, formação de coágulo com maior densidade devido ao menor tamanho da micela, assim como uma maior produção de queijo em relação ao leite de vacas com o genótipo AA para a k-CN (Medrano e AguilarCordoba, 1990 a; Hallén et al., 2007).

Para a $\beta$-LG, o genótipo $\mathrm{AB}$ foi o mais frequente nas raças Girolanda (54\%) e Holandesa (58\%), enquanto na raça Jersey a maior frequência foi do genótipo BB (45\%) (Fig. 1). Frequências similares foram observaram em diversos locais por outros autores.

Rodrigues (2006), ao avaliar rebanhos de Minas Gerais, obteve uma frequência de $57 \%$ para o genótipo $\mathrm{AB}$ da $\beta$-LG na raça Girolanda. Na raça Holandesa, Celik (2003) observou maior frequência $(53 \%)$ do genótipo BB na Nova Zelândia, enquanto Ojala et al. (1997), na California, e Orner e Elmaci (2006), na Turquia, do genótipo $\mathrm{AB}$ (51-56\%). Para a raça Jersey, vários autores verificaram maior frequência para o heterozigoto $\mathrm{AB}$, de $43 \%$ na Holanda (Paterson et al., 1999), 51\% na Nova Zelândia (Hill et al., 1993) e 58\% na Califórnia (Ojala et al., 1997).

Vários estudos foram realizados sobre o efeito dos genótipos da $\beta$-LG sobre a produção de leite. $\mathrm{O}$ genótipo AA tem demonstrado ter efeito favorável sobre a quantidade de proteínas e o rendimento na produção de leite, enquanto os efeitos positivos do genótipo BB têm sido relacionados ao maior teor de gordura (Bovenhuis et al., 1992) e caseína (Lodes et al., 1997). Isso acarreta maior rendimento na produção de queijos e implicações na textura e caracterização sensorial de produtos lácteos. Além disso, o alelo B da $\beta$-LG está relacionado a maior estabilidade térmica do leite (Fox e McSwenney, 2003).

Segundo Molina et al. (2006), há interação entre as variantes genéticas de k-CN e $\beta$-LG, as quais apresentam combinação mais favorável entre a k-CN A e a $\beta$-LG AA, e a k-CN B e a $\beta-L G$ AB para maior conteúdo proteico no leite da raça Holandesa.

Houve associação do genótipo para k-CN com a produtividade $(\mathrm{P}<0,05)$ nas raças Girolanda e Holandesa (Tab. 1). Nos animais da raça Girolanda, o genótipo BB foi o que apresentou maior produção de leite, enquanto na raça Holandesa os genótipos $\mathrm{AB}$ e $\mathrm{BB}$ mostraram maior produção do que os AA. A produtividade leiteira foi associada com os genótipos da $\beta$-LG somente para a raça Jersey, na qual os genótipos $\mathrm{AA}$ e $\mathrm{AB}$ apresentaram a maior produtividade. As diferenças encontradas não foram significativas $(\mathrm{P}>0,05)$ para as raças Holandesa e Girolanda com relação aos genótipos da $\beta$-LG.

Tabela 1. Produtividade média (kg leite/dia) das raças avaliadas de acordo com os genótipos relativos à kappa-caseína e à beta-lactoglobulina

\begin{tabular}{cccc}
\hline Genótipo & Girolando & Holandês & Jersey \\
\hline Kappa-caseína & $10,6 \pm 3,2 \mathrm{ab}$ & $10,7 \pm 3,2 \mathrm{~b}$ & $10,6 \pm 2,7 \mathrm{a}$ \\
AA & $8,4 \pm 1,9 \mathrm{~b}$ & $16,4 \pm 4,2 \mathrm{a}$ & $12,2 \pm 4,1 \mathrm{a}$ \\
AB & $14,4 \pm 0,8 \mathrm{a}$ & $14,9 \pm 3,4 \mathrm{ab}$ & $10,8 \pm 2,6 \mathrm{a}$ \\
BB & & & \\
Beta-lactoglobulina & $6,8 \pm 3,6 \mathrm{a}$ & $12,8 \pm 4,4 \mathrm{a}$ & $10,3 \pm 4,7 \mathrm{ab}$ \\
AA & $10,3 \pm 2,6 \mathrm{a}$ & $14,1 \pm 4,5 \mathrm{a}$ & $12,3 \pm 1,9 \mathrm{a}$ \\
BB & $10,4 \pm 3,4 \mathrm{a}$ & $14,4 \pm 4,1 \mathrm{a}$ & $8,9 \pm 1,4 \mathrm{~b}$ \\
\hline
\end{tabular}

Para cada proteína, valores com letras distintas na coluna diferem entre si $(\mathrm{P}<0,05)$. 
Não há um consenso na literatura sobre a influência dos alelos A e B do gene para a k-CN sobre a produtividade leiteira (Fox e McSwenney, 2003). Alguns estudos com as raças Holandesa e Girolanda, não verificaram correlação entre as variantes genéticas da k-CN e a produtividade (Lin et al., 1986; Ng-Kwai-Hang et al., 1990), enquanto outros sugeriram que, para animais da raça Holandesa, Ayrshire e Jersey, a k-CN AA (Bovenhuis et al., 1992) ou a k-CN AB (Kim et al., 1996) ou a k-CN BB (Pupkova, 1980) são positivamente associadas com a produção leiteira.

Com relação à $\beta$-LG, Jairam e Nair (1983) e Marziali e Ng-Kwai-Hang (1986) observaram maior produção de leite para vacas da raça Holandesa com genótipo BB. Já nos trabalhos de Comberg et al. (1964), Atroshi et al. (1982) e Bovenhuis et al. (1992), a variante A foi relacionada com maior produção de leite em bovinos das raças Jersey e Gir. Cowan et al. (1992) não encontraram diferença na produção leiteira entre os genótipos da beta-lactoglobulina bovina.

Essas diferenças entre estudos com a mesma raça ocorrem, provavelmente, em função de outros fatores, como clima e alimentação (Fox e McSwenney, 2003), os quais podem variar entre os diversos experimentos.

\section{CONCLUSÃO}

No presente estudo, os genótipos AA, AB e BB para a kappa-caseína e para beta-lactoglobulina bovinas foram encontrados em diferentes frequências nas três raças avaliadas. Além disso, foi verificada associação do alelo $\mathrm{B}$ da k-CN com maior produtividade leiteira nas raças Girolanda e Holandesa e do alelo A da $\beta$-LG com maior produtividade leiteira na raça Jersey. Esses resultados indicam que as variantes genéticas da k-CN podem ser usadas como marcadores na seleção para a produtividade leiteira para as raças Girolanda e Holandesa e as variantes da $\beta$-LG nessa seleção para a raça Jersey. O conhecimento desses dados genotípicos permitiria um direcionamento mais adequado dos cruzamentos e a seleção de animais precocemente, contribuindo significativamente para a melhoria na produção de leite nesses rebanhos.

\section{REFERÊNCIAS}

ALEANDRI, R.; BUTTAZZONI, L.G.; SCHNEIDER, J.C. et al. The effects of milk protein polymorphisms on milk components and cheese producing ability. J. Dairy Sci., v.73, p.241-255, 1990.

ALEXANDER, L.J.; STEWART, A.F.; MACKINLAY, A.G.; KAPELINSKAYA, T. V. Isolation and characterization of the bovine kappacasein gene. Eur. J. Biochem., v.178, p.395-401, 1988.

ASCHAFFENBURG, R.; DREWRY, J. Occurrence of different beta-lactoglobulins in cow's milk. Nature, v.176, p.218-219, 1955.

ATROSHI, F.; KANGASNIEMI, R.; HONKANONBUZALSKI, T. Betalactoglobulin phenotypes in Finnish Ayrshire and Friesian cattle with special reference to mastitis indicators. Acta Vet. Scand., v.22, p.135, 1982.

BOTARO, B.G.; LIMA, Y. V. R.; CORTINHAS, C.S. et al. Effect of the kappa-casein gene polymorphism, breed and seasonality on physicochemical characteristics, composition and stability of bovine milk. Rev. Bras. Zootec., v.38, p.2447-2454, 2009.

BOVENHUIS, H.; JOHAN, A.M.; ARENDONK, V.; KORVER, S. Association between milk protein polymorphisms and milk production traits. J. Dairy Sci., v.75, p.2549-2559, 1992.

BUCHBERGER, J. Genetics polymorphisms of milk protein: differences between breeds. Bull. Int. Dairy Fed., n.304, p.5-6, 1995.

CELIK, S. Beta-Lactoglobulin genetic variants in Brown Swiss breed and association with compositional properties and rennet clotting time of milk. Int. Dairy J., v.13, p.727-731, 2003.

COMBERG, G.H.; MEYER, H.; GROWING, M. Correlation between beta-lactoglobulin types in cattle and age at first calving, milk yield and fat contents and distribution of protein fraction. Zuchtungskunde, v.36, p.248-255, 1964.

COWAN, C.M.; DENTINE, M.R.; COYLE, T. Chromosome substitution effects associated with kcasein and $\beta$-lactoglobulin in Holtein cattle. J. Dairy Sci., v.75, p.1097-1104, 1992.

FOX, P.F.; McSWEENEY, P.L.H. Advanced dairy chemistry: proteins. 3. ed. New York: Kluwer Academic, 2003. v.1.740p.

HALLEN, E.; ALLMERE, T.; NASLUND, J. et al. Effect of genetic polymorphism of milk proteins on rheology of chymosin-induced milk gels. Int. Dairy J., v.17, p.791-799, 2007. 
HILL, J.P. The relationship between betalactoglobulin phenotypes and milk composition in New Zealand dairy cattle. J. Dairy Sci., v.76, p.281286, 1993.

HILL, J.P.; BOLAND, M.J.; CREAMER, L.K. et al. Effect of the bovine beta-lactoglobulin phenotype on the properties of beta-lactoglobulin, milk composition and dairy products. Macromol. Inter. Food Technol., v.650, p.281-294, 1996.

JAIRAM, B.T.; NAIR, P.G. Genetic polymorphisms of milk protein and economic characters in dairy animals. Indian J. Anim. Sci., v.53, p.1-8, 1983.

KIM, S.; NG-KWAI-HANG, K.F.; HAYES, J.F. The relationship between milk protein phenotypes and lactation traits in Ayrshires and Jerseys. Asian-Aust. J. Anim. Sci., v.9, p.685-693, 1996.

LIN, C.Y.; McALLISTER, K.F.; NG-KWAIHANG, K.F. Effects of milk protein loci on first lactation production in dairy cattle. J. Dairy Sci., v.69, p.704712, 1986.

LODES, A.; BUCHEBERGER, J.; KRAUSE, I. et al. The influence of genetic variants of milk proteins on the compositional and technological properties of milk: 3. Content of protein, casein, whey protein and casein number. Milchwissenschaft, v.52, p.3-8, 1997.

MAO, I.L.; BUTTAZOZONI, L.G.; ALEANDRI, R. Effects of Polymorphic milk protein genes on milk yield and composition traits in Holstein cattle. Acta Agr. Scand., v.42, p.1-7, 1992.

MARZIALI, A.S.; NG-KWAIN-HANG, K.F. Effects of milk composition and genetic polymorphism on cheese composition. J. Dairy Sci., v.69, p.2533-2542, 1986.

MEDRANO, J.F.; AGUILAR-CORDOVA, E. Genotyping of bovine kappa-casein loci following DNA sequence amplification. Bio/Technol., v.8, p.144-146, 1990a.

MEDRANO, J.F.; AGUILAR-CORDOVA, E. Polymerase chain reaction amplification of bovine $\beta$ lactoglobulin genomic sequences and identification of genetic variants by RFLP analysis. Anim. Biotechnol., v.1, p.73-77, 1990b.

MOLINA, L.H.; KRAMM, J.; BRITO, C. et al. Protein composition of milk from Holstein-Friesian dairy cows and its relationship with the genetic variants A and B of kappa-casein and betalactoglobulin (Part I). Int. J. Dairy Technol., v.59, p.183-187, 2006

NG-KWAI-HANG, K.F.; HAYES, J.F.; MOXLEY, J.E.; MONARDES, H.G. Relationships between milk protein polymorphisms and major milk constituents in Holstein-Friesian cows. J. Dairy Sci., v.69, p.22-26, 1986.
NG-KWAI-HANG, K.F.; HAYES, J.F.; MOXLEY, J.E.; MONARDES, H.G. Variation in milk protein concentration associated with genetic polymorphism and environmental factors. J. Dairy Sci., v.70, p.563570, 1987.

NG-KWAI-HANG， K.F.; MONARDES， H.G.; HAYES, J.F. Association between genetic polymorphism of milk proteins and production traits during three lactations. J. Dairy Sci., v.73, p.3414$3420,1990$.

OJALA, M.; FAMULA, T.R.; MEDRANO, J.F. Effects of milk protein genotypes on the variation for milk production traits of Holstein and Jersey cows in California. J. Dairy Sci., v.80, p.1776-1785, 1997.

ORNER, Y.; ELMACI, C. Milk protein polymorphisms in Holstein cattle. Int. J. Dairy Technol., v.59, p.180-182, 2006.

PATERSON, G.R.; MacGIBBON, A.K.H.; HILL, J.P. Influence of kappa-casein and beta-lactoglobulin phenotype on the heat stability of milk. Int. Dairy J., v.9, p.375-376, 1999.

PUPKOVA, G.V. Milk protein polymorphism and milk production of Estonian Black Pied cows. Dairy Sci. Abstr., v.45, p.6620, 1980.

RODRIGUES, S.G. Estudo das frequências dos alelos $A \quad e \quad B$ dos genes da kappa-caseína e betalactoglobulina e suas associações com produção de leite em bovinos $F_{I}$ Girolando. 2006. 30f. Tese (Doutorado em Ciência Animal) - Universidade Federal de Minas Gerais, Belo Horizonte.

VALENTE, E.P. Levantamento das frequências dos fenogrupos do sistema $B$ de grupos sanguíneos e dos alelos $A$ e $B$ do gene da k-caseína em populações das raças Holandesa e Gir do Estado de Minas Gerais. 1996. 69f. Dissertação (Mestrado em Medicina Veterinária) - Escola de Veterinária da Universidade Federal de Minas Gerais, Belo Horizonte.

VAN DER BERG, G.; ESCHER, J.T.M.; DE KONNING, P.J.; BOVENHUIS, H. Genetic polymorphism of $\kappa$ - casein and $\beta$-lactoglobulin in relation to milk composition and processing. Neth. Milk Dairy J., v.46, p.145-168, 1992.

WALSTRA, P.; WOUTERS, J.T.M.; GEURTS, T.J. Dairy science and technology. 2nd ed. Boca Raton: Taylor \& Francis, 2006. 782p.

WATSON, J.D.; BERRY, A. DNA: the secret of life. New York: Alfred A. Knopf, 2006. 446p. 